\title{
PENINGKATAN DAYA JUAL ANEKA PRODUK OLAHAN MAKANAN MELALUI TEKNIK PENGEMASAN PRODUK
}

\section{Yuniawan Hidayat, ${ }^{1,2}$, Eddy Triharyanto ${ }^{1,3}$}

1) Pusat Pengembangan Kewirausahaan, LPPM, Universitas Sebelas Maret

2) Fakultas Matematika dan IPA, Universitas Sebelas Maret

3) Fakultas Pertanian, Universitas Sebelas Maret

Email: yuniawan.hidayat@mipa.uns.ac.id

\begin{abstract}
ABSTRAK
Desa Jendi dan Desa Keloran, Wonogiri merupakan desa yang memproduksi aneka keripik hasil pertanian. Di Desa Jendi terdapat Lembaga Pemberdayaan Kesejahteraan Keluarga (LPKK) Putri Mandiri yang memproduksi berbagai keripik seperti keripik tempe dan keripik singkong. Di Desa Keloran terdapat LPKK Sumber Rejeki yang memproduksi keripik singkong yang telah dipresto terlebih dahulu. Permintaan keripik singkong di kedua mitra semakin meningkat. Akan tetapi, kemasan yang digunakan masih sangat sederhana. Kemasan saat ini masih menggunakan plastik yang diberi label. Padahal untuk menunjang pemasaran, kemasan harus dibuat semenarik mungkin. Tujuan dari pengabdian ini adalah untuk meningkatkan kualitas kemasan agar dapat dipasarkan di pusat oleh-oleh dan menjadi produk unggulan Wonogiri serta melatih para anggota-anggota LPKK mengenai pemasaran produk. Oleh karena itu, tim pengabdi memberikan solusi berupa pemberian Teknologi Tepat Guna kepada kedua mitra. Teknologi Tepat Guna tersebut adalah Hand Sealer, Cup Sealer, Spinner dan Dus Kemasan. Selain pemberian TTG, dilakukan pula pelatihan inclass mengenai manajemen keuangan, pengemasan dan manajemen pemasaran.
\end{abstract}

Kata kunci: keripik, kemasan, Wonogiri

\section{ABSTRACT}

Jendi Village and Keloran Village, Wonogiri are villages which produce various chips from agricultural product. In Jendi Village, there is Lembaga Pemberdayaan Kesejahteraan Keluarga (LPKK) Putri Mandiri producing a variety of chips, that is, tempeh chips and cassava chips. In Keloran Village, there is LPKK Sumber Rejeki producing cassava chips that has been presto before. The demand of casssava chips of two partners is more increasing. But, packing used is still very simple. Today, the partners use plastic labeled for packaging. Whereas to support marketing, packaging must be made as attractive as possible. The purposes of this public service are to improve the quality of packaging in order to be marketed in center of gifts, to be leading product of Wonogiri, and to train the 
members of LPKK about product marketing. Therefore, the team of the public service give solutions in the form of giving Teknologi Tepat Guna for the two partners. Teknologi Tepat Guna are hand sealer, cup sealer, spinner and packing box. The team also performed inclass training about financial management, packaging, and marketing management.

Keyword: chips, packaging, Wonogiri

\section{LATAR BELAKANG}

Wonogiri dikenal dengan panganan aneka keripiknya. Banyak masyarakat di daerah Wonogiri yang memproduksi aneka macam keripik dari bahan baku hasil pertanian baik dalam skala besar maupun skala kecil. Keripik-keripik tersebut kemudian dipasarkan ke pengepul atau toko oleh-oleh langsung.

Desa Jendi dan Keloran merupakan dua desa di Kecamatan Selogiri yang memproduksi olahan makanan berupa keripik. Bangkitnya industri kecil di Desa Jendi ditandai dengan mulai berdirinya usaha keripik tempe dan keripik singkong yang dirintis oleh ibu-ibu di Desa Jendi. Selain menambah penghasilan bagi keluarga, usaha keripik tempe dan keripik singkong ini bisa menjadi salah satu solusi pemerintah daerah untuk mengatasi urbanisasi dan meningkatkan kesejahteraan masyarakat, khususnya di Wonogiri. Ibu-ibu ini tergabung kedalam Lembaga Pemberdayaan Kesejahteraan Keluarga (LPKK) Putri Mandiri.

Usaha keripik tempe di Desa Jendi berawal dari berlimpahnya ketersediaan tempe di desa ini. Tempe merupakan makanan yang dibuat dari fermentasi terhadap biji kedelai atau beberapa bahan lain yang menggunakan beberap ajenis jamur Rhizopus (Trielal,1993). Beberapa penelitian menunjukkan bahwa zat gizi tempe lebih mudah dicerna, diserap, dan dimanfaatkan tubuh dibandingkan dengan yang ada dalam kedelai. Ini telah dibuktikan pada bayi dan anak balita penderita gizi buruk dan diare kronis (Partawihardja, 1999). Karena tempe merupakan makanan fermentasi yang didalamnya terdapat jamur Rhizopus sp yang masih aktif sehingga tempe tidak memiliki daya simpan yang lama. Jika terlalu lama disimpan tanpa diolah, tempe akan menjadi busuk (Astuti, 1996).

Untuk memperpanjang daya simpan tempe sehingga tempe tidak terbuang sia-sia, ibu-ibu yang tergabung dalam Lembaga Pemberdayaan Kesejahteraan Keluarga (LPKK) Putri Mandiri di Desa Jendi mengolah tempe menjadi keripik tempe beraneka rasa. Selain keripik tempe, usaha pembuatan keripik singkong juga dirintis oleh ibu-ibu di Desa Jendi. Singkong merupakan tanaman yang sangat mudah ditemukan di Desa Jendi karena hamper 75\% tegalan warga ditanami oleh singkong. Hal ini menjadi peluang emas ibu-ibu untuk memanfaatkan singkong menjadi makanan yang enak dan digemari oleh masyarakat luas. Memanfaatkan hasil pertanian dari tegalan mereka sendiri 
diharapkan keripik singkong dapat memberikan keuntungan yang tinggi untuk menambah pendapatan dan taraf hidup warga Desa Jendi Kecamatan Selogiri Kabupaten Wonogiri. Setiap hari ibu-ibu di Desa Jendi mampu menghasilkan keripik tempe dan keripik singkong sekitar $5 \mathrm{~kg}$.

Ibu-ibu di Desa Keloran yang tergabung kedalam LPKK Sumber Rejeki juga memproduksi olahan keripik dari singkong presto. Desa ini memiliki potensi yang menjanjikan sebagai penghasil tanaman ubi kayu (singkong). Singkong biasanya hanya ditanam di lahan kebun belakang rumah warga. Hasil panen singkong dari kebun lebih sedikit dan biasanya hanya diolah menjadi gaplek, untuk dikonsumsi sendiri, jika peralatan memadai ibu-ibu rumah tangga akan mengolah singkong menjadi keripik dan dikemas seadanya kemudian dijual di pasar atau dititipkan ke warung-warung makan. Melihat prospek tanaman singkong di masa mendatang semakin cerah, Pemerintah Kabupaten Wonogiri memberi prioritas untuk pengembangannya. Kebijakan yang diambil adalah melakukan pemberdayaan petani singkong dengan bantuan bibit unggul serta pendampingan pola tanam.

Aneka keripik yang diproduksi oleh LPKK Putri Mandiri dan LPKK Sumber Rejeki saat ini hanya memiliki satu varian rasa, yakni rasa original. Kemasan yang digunakan oleh kedua mitra ini pun masih sangat sederhana. Pengemasan hanya menggunakan plastik yang diberi label. Padahal untuk menunjang pemasaran diperlukan kemasan yang menarik. Tujuannya adalah agar konsumen tertarik terhadap produk yang dijual dan meningkatkan harga jual, karena karena produk yang dibuat juga harus memenuhi kepuasan konsumen (Suranto, 2015). Oleh karena itu, masih perlu dorongan dan pendampingan untuk LPKK Putri Mandiri dan LPKK Sumber Rejeki dalam hal packaging dan pemasaran.

\section{METODE PENGABDIAN}

Metode yang digunakan untuk membantu mengatasi persoalanpersolan yang telah disepakati diatas adalah melalui pelatihan packaging, pelatihan pemasaran, pemberian bantuan dukungan alat packaging, dan pendampingan:

1. Pelatihan pembuatan keripik dengan berbagai varian rasa. Varian rasa yang akan dicobakan adalah rasa original, asin, pedas dan balado. Setelah dirasa cukup baik, produk-produk aneka rasa tersebut dipasarkan.

2. Pelatihan packaging diakukan sebanyak 2 kali. Pelatihan packaging dilakukan baik secara inclass maupun outclass. Pada pelatihan inclass diberikan materi mengenai cara dan proses pengemasan yang baik. Sedangkan pada pelatihan outclass, akan diberikan pelatihan cara pengemasan menggunakan kemasan kardus. 
3. Pelatihan pemasaran dilakukan guna meningkatkan pengetahuan anggota-anggota LPKK mengenai manajemen dan system pemasaran. Pelatihan pemasaran ini dilakukan secara inclass.

4. Stimulan modal berupa peralatan teknologi tepat guna yang mendukung proses packaging. Stimulan berupa hand sealer dan kemasan kardus yang diberikan kepada anggota LPKK Sumber Rejeki dan LPKK Putri Mandiri.

5. Monitoring dan Evaluasi, dilakukan untuk mengevaluasi kemasan keripik dan manajemen pemasaran.

\section{HASIL PENGABDIAN}

1. Koordinasi Kegiatan

Koordinasi kegiatan ini dilaksanakan pada tanggal 14 Mei 2016. Dalam koordinasi kegiatan ini didapatkan hasil sebagai berikut :

a. Produk-produk yang dihasilkan di kedua desa tidak hanya keripik, namun ada pula produk makanan lain seperti onde-onde, jamur crispy, gethuk lindri, gethuk goreng, jamu dan sari kacang hijau.

b. Kemasan hanya dibungkus menggunakan plastik dengan label yang masih sederhana. Label masih menggunakan kertas yang difotokopi.

c. Produk seperti onde-onde dan jamur crispy masih mengandung banyak

minyak jadi masih perlu penirisan.

d. Teknologi Tepat Guna yang akan disewakan kepada mitra antara lain: cup sealer, mesin pemiris minyak, kemasan, dan sticker.

2. Pelatihan inclass

Pelatihan inclass dilaksanakan pada tanggal 12 Agustus 2016. Pelatihan inclass ini bertujuan untuk melatih para anggota LPKK Putri Mandiri dan Sumber Rejeki mengenai manajemen keuangan, pengemasan, dan pemasaran. Materi pelatihan inclass ini diberikan oleh Ir. MA. Martina Andriani, MS. Dalam pelatihan ini disampaikan proses pengemasan yang baik, yang sesuai dengan standar mutu. Melalui pelatihan ini diharapkan para anggota LPKK mampu memasarkan produknya hingga ke toko-toko besar melalui pengemasan yang baik.

a. Pelatihan Manajemen Keuangan

Peserta pelatihan diberikan bekal mengenai pencatatan administrasi keuangan sederhana. Administrasi keuangan sederhana yang dimaksudkan adalah proses pemasukan dan pengeluaran proses produksi aneka olahan makanan.

b. Pelatihan Pemasaran

Pelatihan pemasaran dimaksudkan untuk 
meningkatkan pengetahuan mitra mengenai bagaimana cara pemasaran dengan baik. Peserta pelatihan dibekali pengetahuan mengenai penerapan sistem pemasaran bagi usaha kecil. Hal yang perlu diperhatikan dalam pemasaran diantaranya adalah kontinyuitas produksi, dan pengemasan.

c. Pelatihan Pengemasan

\section{Pada}

dasarnya pengemasan merupakan kunci utama dari sebuah produk. Apabila suatu produk yang sudah memiliki rasa yang enak namun pengemasannya kurang menarik akan mengakibatkan konsumen tidak tertarik untuk membeli produk tersebut. Sebaliknya apabila sebuah produk telah dikemas dengan menarik, maka konsumen akan datang sendiri untuk membeli produk tersebut. Syarief et al. (1989) yang menyatakan kemasan yang baik harus mempunyai fungsi efisien dan ekonomis. Efesien maksudnya penggunaan kemasan pada produk kemudahan memberikan konsumen. kepada

Tolo-toko besar seperti Ganeps, Javelin, dan lain sebagainya mengutamakan kemasan dalam menerima produk untuk dijual di tokonya. Pada pelatihan mengenai pengemasan dijelaskan mengenai produkproduk yang sudah berhasil masuk ke toko-toko besar dengan pengemasan menggunakan plastik ataupun kardus.
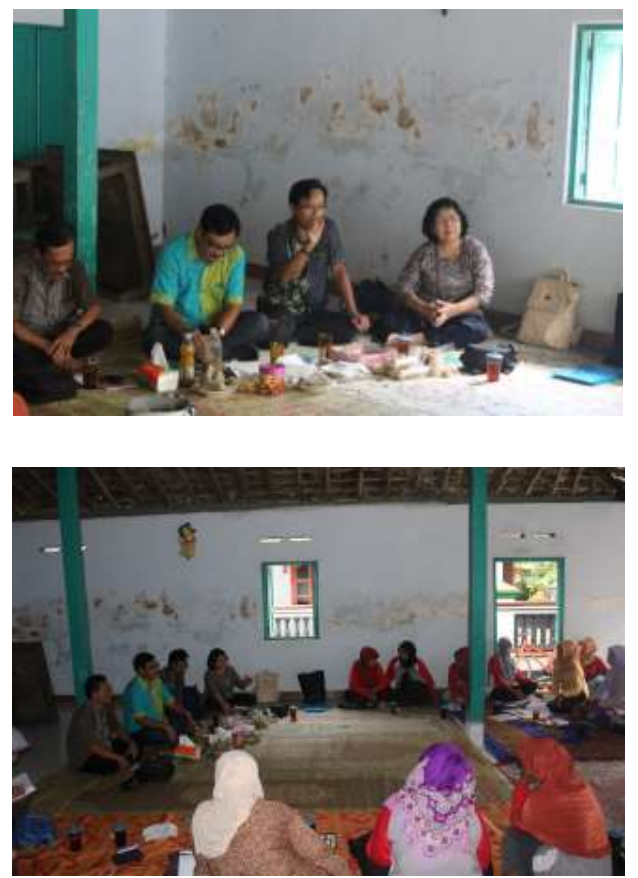

Gambar 1. Pelatihan Inclass di Desa Jendi

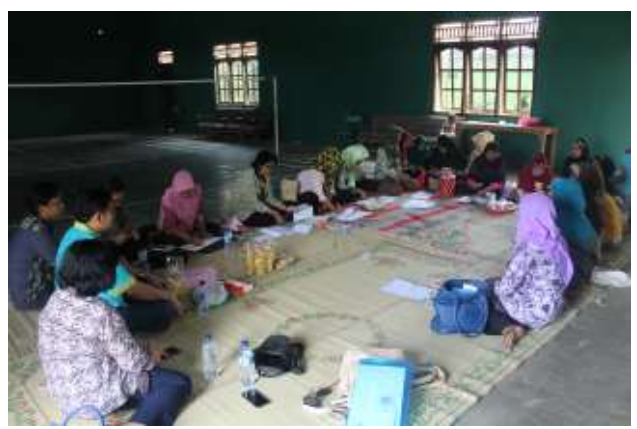




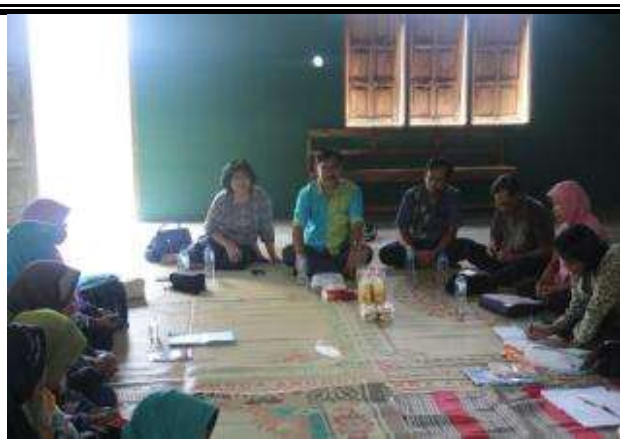

Gambar 2. Pelatihan Inclass di Desa Keloran

3. Pembuatan Kemasan Kardus dan Sticker

Kemasan getuk diperbaiki dengan menambahkan kardus sebagai kemasan sekunder. Hal ini bertujuan untuk meningkatkan nilai jual produk getuk sehingga diharapkan penjualan getuk dapat meningkat. Di samping itu, penambahan kemasan kardus diharapkan dapat memperluas area penjualan dan dapat membantu memperpanjang umur simpan produk. Desain kemasan sekunder (kardus) getuk dapat dilihat pada Gambar 3 berikut.

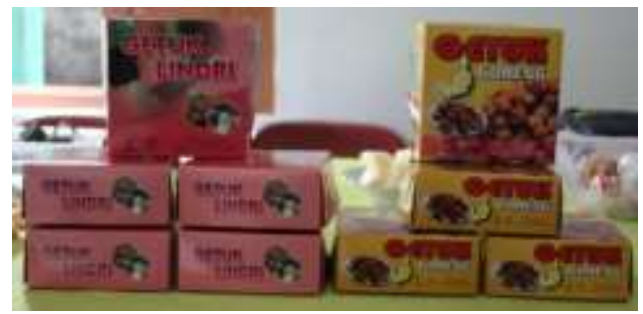

Gambar 3.Desain Kardus Getuk Lindri dan Getuk Goreng

Selain perbaikan kemasan getuk menggunakan kardus, olahan makanan/minuman lain juga diperbaiki menggunakan sticker. Sticker dibuat seukuran dengan ukuran plastik kemasan. Dengan penggunaan sticker ini diharapkan mampu meningkatkan daya jual produk dan memperindah kemasan. Desain sticker dapat dilihat pada Gambar 4 berikut.
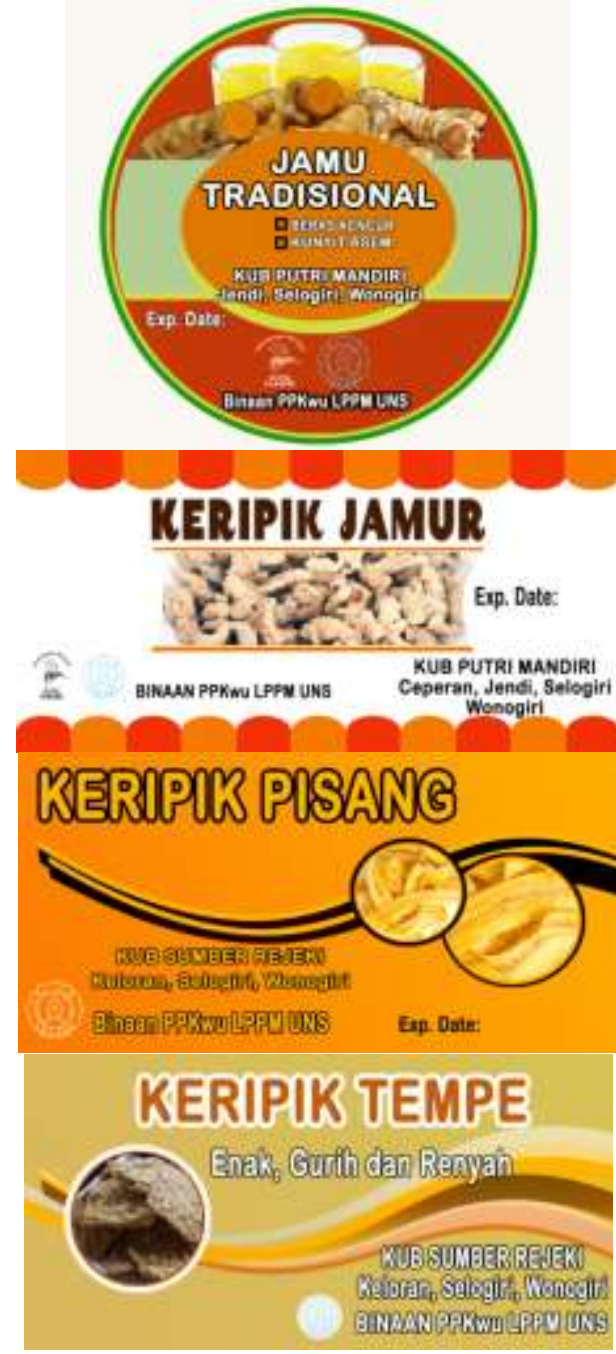

Gambar 4. Desain Sticker

4. Penyediaan Teknologi Tepat Guna

Teknologi yang diberikan kepada mitra adalah cup sealer, spinner (peniris minyak), dan hand sealer. Penggunaan cup sealer akan menghasilkan kemasan produk minuman yang 


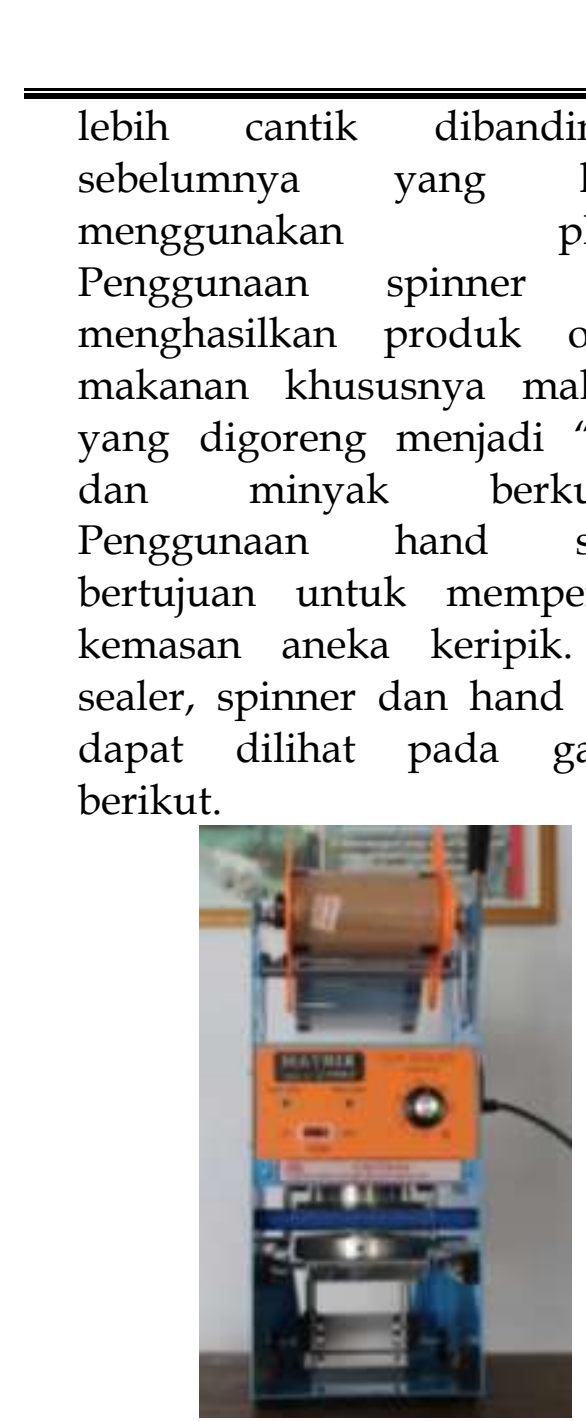

(a)

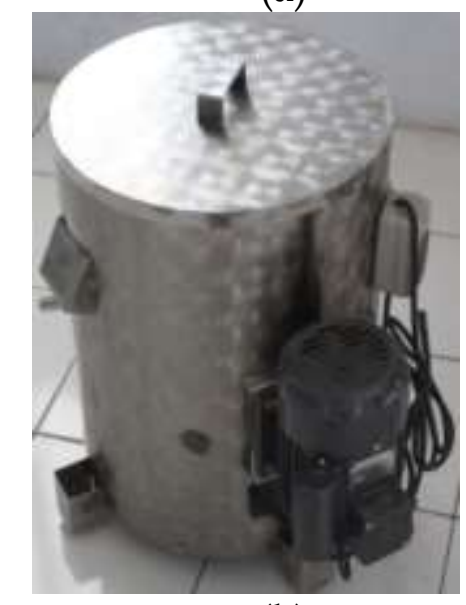

(b)

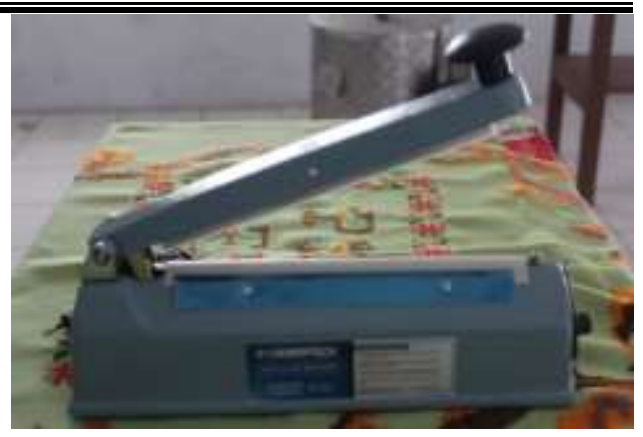

(c)

Gambar 5. (a) Cup Sealer, (b) Spinner, (c) Hand sealer

5. Pelatihan Outclass

Tujuan

diadakannya pelatihan outclass adalah untuk memberikan skill/keterampilan pada wanita yang tergabung dalam LPKK Putri Mandiri dan Sumber Rejeki agar mitra mengetahui secara terperinci tentang teknologi tepat guna dan penggunaannya untuk pengemasan produk. Mitra dikenalkan pada alat cup sealer, alat peniris minyak (spinner), dan hand sealer. Pada pelatihan ini juga dijelaskan cara pengemasan menggunakan kardus. 
Yuniawan Hidayat, Peningkatan Daya Jual Aneka Produk Olahan Makanan Melalui Teknik Pengemasan Produk

ISSN : 1979-861X

e-ISSN : 2549-1555

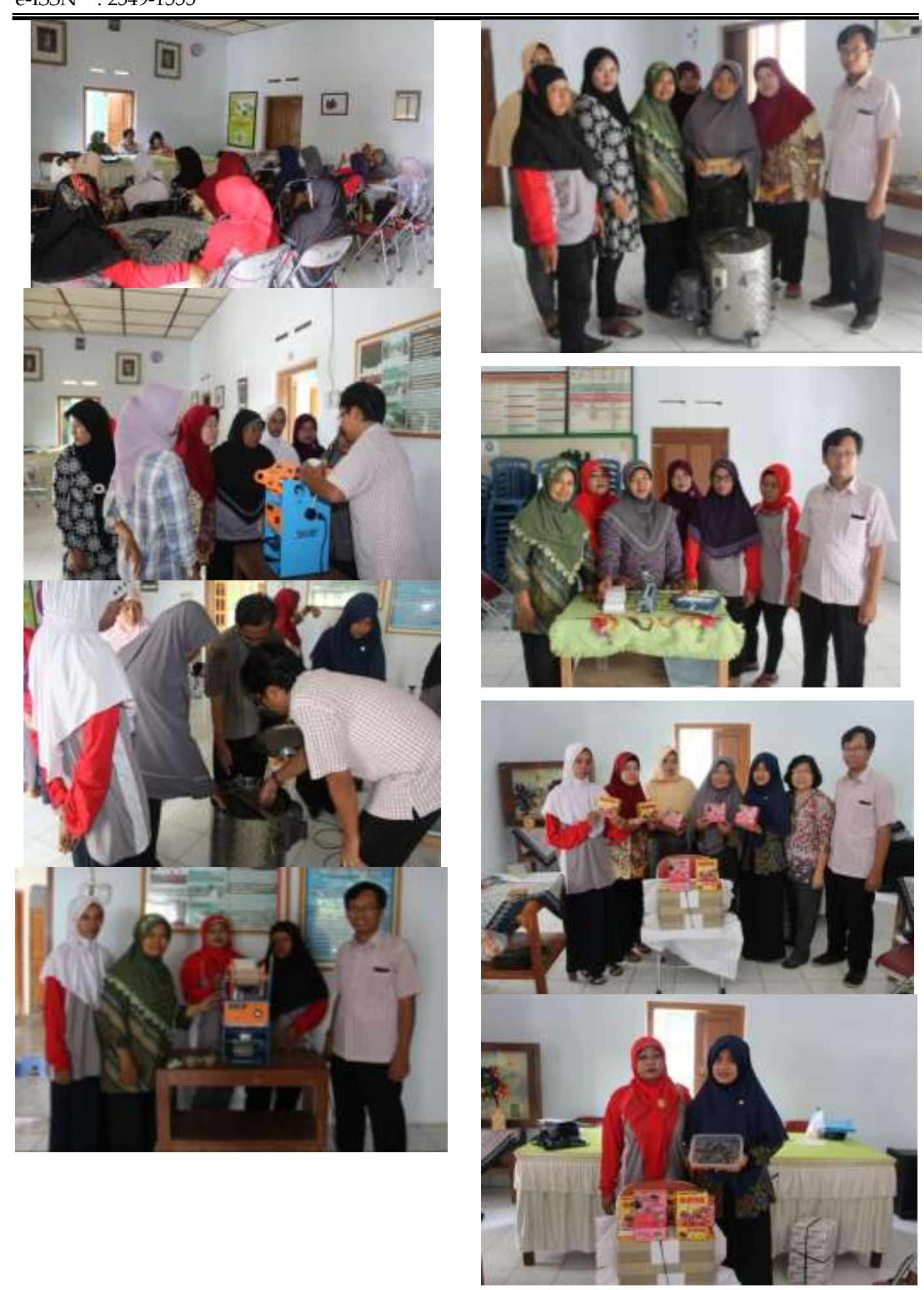

Gambar 6. Pelatihan Outclass di

Desa Jendi 


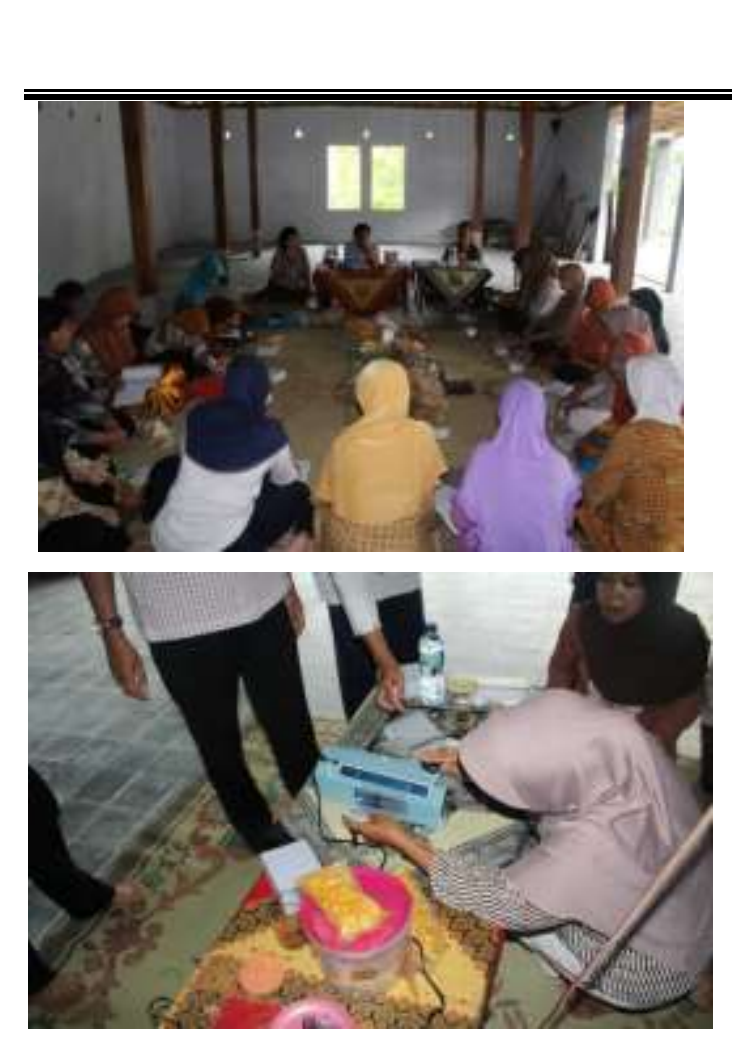

ISSN : 1979-861X e-ISSN : 2549-1555

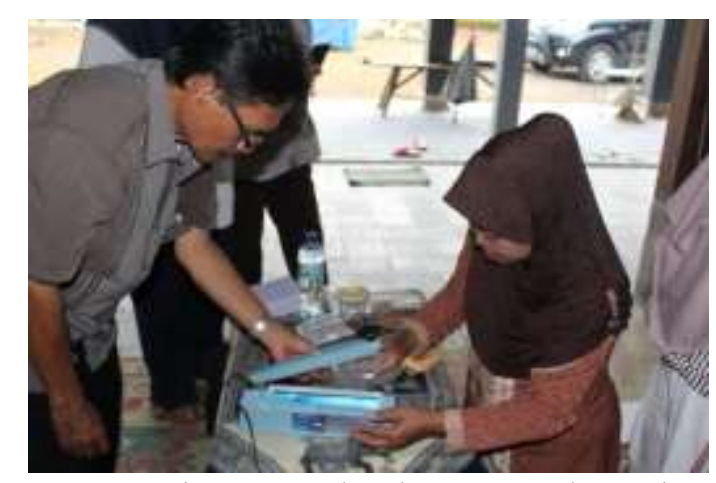

Gambar 7. Pelatihan Outclass di Desa Keloran

\section{KESIMPULAN}

1. Kegiatan IbM yang telah dilakukan adalah koordinasi pelaksanaan kegiatan, pelatihan inclass, pembuatan kemasan, penyediaan teknologi tepat guna dan palatihan outclass.

2. Melalui pembuatan kemasan kardus yang telah dilakukan diharapkan dapat menarik konsumen, memperbaiki kualitas penyimpanan, memperluas pangsa pasar dan meningkatkan omset

3. Teknologi Tepat Guna yang telah diberikan adalah cup sealer, hand sealer, dan spinner yang diharapkan mampu meningkatkan kualitas produk.

\section{DAFTAR PUSTAKA}

Suranto, A. M. Riza. 2005. Penentuan strategi Pemasaran Berdasarkan Perilaku Konsumen dengan Metode Diskriminan. Jurnal Ilmiah Teknik Industri Vol. 04 (1). Hal $18-27$.

Syarief Rizal S,. Santausa dan St. Isyana B. 1989. Teknologi Pengemasan Pangan. Laboraturium Rekayasa Proses Pangan, Pusat Antar Universitas Pangan dan Gizi. Institut Pertanian Bogor. Bogor.

Wiji Nurhayat. 2014. Kementan Akui Banyak Petani Singkong Jatuh Miskin. (http:/ / us.finance.detik.com/ $\mathrm{read} / 2014 / 05 / 14 / 152840 / 258$ 2624/4/kementan-akuibanyak-petani-singkongjatuh-miskin). Diakses tanggal 5 Maret 2015 pukul 13.04 WIB. 